\title{
FAILURE OF ELECTRIC MOTOR-DRIVEN PUMP BOEING SYSTEM 737-800
}

\author{
Anggun Nurul Hidayah \\ Jurusan Teknik Dirgantara, Sekolah Tinggi Teknologi Adisutjipto \\ hidayahanggun25@gmail.com
}

\begin{abstract}
This study aims to determine the results of the analysis of the causes a failure that occurred in the Electric Motor-Driven Pump system on an aircraft. Boeing 737-800. The data used is in the form of a Pilot Report from the Batik airline. Water in the period 2013 to 2020.The method used in this research is Failure Mode and Effect Criticality Analysis (FMECA). FMECA is a method used to analyze the causes of damage to a system / component,along with the effects if there is damage to the system / component. The first step in this research is to find case data happened to the hydraulic system (ATA 29) on the airline Batik Air, then perform data processing. From the results of the analysis, the results of the RPN value on Electric Motor-Driven.The highest pump is because EMDP cannot supply pressure to the system. Based on the RPN calculation, the RPN value was obtained at 12. This value obtained from the matrix in the safety standard manual from Batik Air.
\end{abstract}

Keywords: Electric Motor-Driven Pump, Failure Mode and Effect Criticality

\section{Latar Belakang}

Pesawat terbang merupakan moda transportasi yang popularitasnya tidak pernah menurun. Terbukti, kebutuhan masyarakat akan berpergian jarak jauh dalam waktu singkat, merupakan alasan utama mengapa alat transportasi ini sangat diminati. Tingkat resiko kecelakaan yang rendah, serta kenyamanan dalam berpergian juga menjadi faktor pendukung untuk masyarakat umum. Boeing 737-800 memiliki 3 (tiga) sistem hidrolik yaitu, main hydraulic system, ground servicing system, dan auxiliary hydraulic system. Main system terdiri dari sistem A yang menggerakkan komponen pada bagian kiri pesawat dan sistem B yang menggerakan komponen pada bagian kanan pesawat. Ground servicing mengisi seluruh reservoir hydraulic dari satu sentral lokasi. Sedangkan auxiliary hydraulic system terdiri dari standby syste [1]. Electric Motor-Driven Pump (EMDP) merupakan bagian utama dari sistem hidrolik yang berfungsi sebagai penyuplai hidrolik bertekanan ke sistem A dan sistem B. Ada beberapa faktor yang menyebabkan terjadinya kegagalan system pada EMDP tersebut. Program perawatan adalah suatu kumpulan tugas-tugas perawatan yang harus dilakukan pada pesawat dalam interval tertentu. Tugas-tugas perawatan ini meliputi seluruh sistem dan struktur yang ada pada suatu pesawat [2][3]. Setiap perusahaan manufaktur pesawat terbang selalu memberikan panduan atau petunjuk dalam perawatan pesawat terbang mereka, yaitu salah satunya dalam Aircraft Maintenance Manual (AMM). Selain itu setiap perusahaan penerbangan yang membeli pesawat juga memperoleh Maintenance Planning Document (MPD) dan Maintenance Review Board (MRB) dengan logika Maintenance Steering Group (MSG) dan pengalaman dari perusahaan penerbangan, ketiga pedoman tersebut diolah sesuai dengan aturan kelayakan udara masing-masing negara sehingga menghasilkan sebuah program perawatan yang sesuai untuk perusahaan penerbangan yang bersangkutan. Perawatan merupakan suatu kegiatan yang diarahkan pada tujuan untuk menjamin kelangsungan fungsional suatu sistem produksi sehingga dari sistem produksi itu dapat menghasilkan output sesuai dengan yang dikehendaki. Sistem perawatan dapat dipandang sebagai bayangan dari sistem produksi, di mana apabila sistem produksi beroperasi dengan kapasitas yang sangat tinggi maka akan lebih intensif 
.Perawatan meliputi semua tindakan yang diperlukan untuk memelihara sistem atau produk,dalam mengembalikannya ke kondisi serviceable [4][5]. Perawatan dikategorikan sebagai berikut

a. Preventive Maintenance

Termasuk semua tindakan perawatan terjadwal yang dikerjakan untuk memelihara sistem atau yang dikerjakan untuk memelihara sistem atau produk ke dalam kondisi yang telah ditentukan.Perawatan preventive dibagi menjadi perawatan periodic (penggantian periodik atau overhaul) dan on-condition. Perawatan periodic atau disebut juga Hard-Time dimaksudkan untuk mecegah kegagalan fungsional. Sedangkan On-Condition dimaksudkan untuk mengantisipasi kegagalan potensial yang sudah terdeteksi agat tidak menjadi kegagalan fungsional.Hard-Time (HT) merupakan batas waktu (interval) maksimum untuk melakukan tugas perawatan. Interval ini biasanya untuk inspeksi periodik, overhaul, tetapi juga berlaku untuk maksimum umur sebuah part atau unit (life limit).On-Condition (OC) merupakan perawatan yang memerlukan inspeksi atau tes berulang untuk menentukan kondisi dari unit atau sistem.

b. Corrective Maintenance

Meliputi semua tindakan perawatan tak terjadwal yang dikerjakan sebagai akibat adanya kerusakan sistem atau produk, untuk mengembalikannya ke kondisi yang telah ditentukan. Siklus perawatan korektif termasuk lokalisasi dan isolasi kerusakan, disassembly, pelepasan dan penggantian, atau repair, reassembly, dan verifikasi kondisi serta pemeriksaan. Corrective Maintenance biasanya juga disebut condition monitoring, dimaksudkan untuk "mengobati" kegagalan fungsional yang sudah terjadi.

c. Condition Monitoring (CM) adalah proses perawatan primer, dimana data dari seluruh komponen yang telah dijadikan item spesifik dalam servis dianalisis untuk menunjukkan apakah diperlukan tindakan teknis. Bukan proses perawatan preventive, namun kondisi pemeliharaan yang di pantau memungkinkan kegagalan terjadi dan bergantung pada analisis informasi dari pengalaman pengoperasian untuk menunjukkan aksi atau tindakan yang diperlukan dalam perawatan.

\section{Metodologi Penelitian}

Dengan adanya permasalahan pada sistem Electric Motor-Driven Pump yang sering terjadi berdasarkan Pilot Report, maka diperlukan suatu analisis untuk mengevaluasi prestasi sebuah sistem guna mengantisipasi kemungkinan kegagalan yang terjadi. Metode analisis data merupakan proses penyusunan data agar mampu diterjemahkan. Kegiatan menganalisis data meliputi mencari data, mengerjakan data, menatanya, membaginya menjadi satuan-satuan yang dapat dikelola, mencari pola, menemukan apa yang perlu dilaporkan. Teknik analisis yang dipakai untuk menganalisa yang sesuai berupa metode analisis Failure Mode and Effect Analysis (FMEA) dan Pareto Analysis sebagai perumusan dasar dalam melakukan analisa untuk pelaksanaan yang sesuai untuk sistem Electric Motor-Driven Pump. Dengan melihat hasil analisa dan pemahaman terhadap proses kerja sistem Electric Motor-Driven Pump maka dapat diketahui output yang harus diteliti [6][7].Data merupakan sampel data yang akan dianalisis sebagai input data Microsoft Excel dalam menganalisis frekuensi kerusakan menggunakan diagram Pareto. Data input yang digunakan adalah data yang diambil berdasarkan Pilot Report pesawat Boeing 737-800 ATA 29 Hydraulic System periode 2013 sampai 2020 untuk selanjutnya diklasifikasikan berdasarkan kerusakan yang sesuai yaitu pada bagian Electric Motor-Driven Pump untuk menentukan frekuensi kerusakan [8][9] 


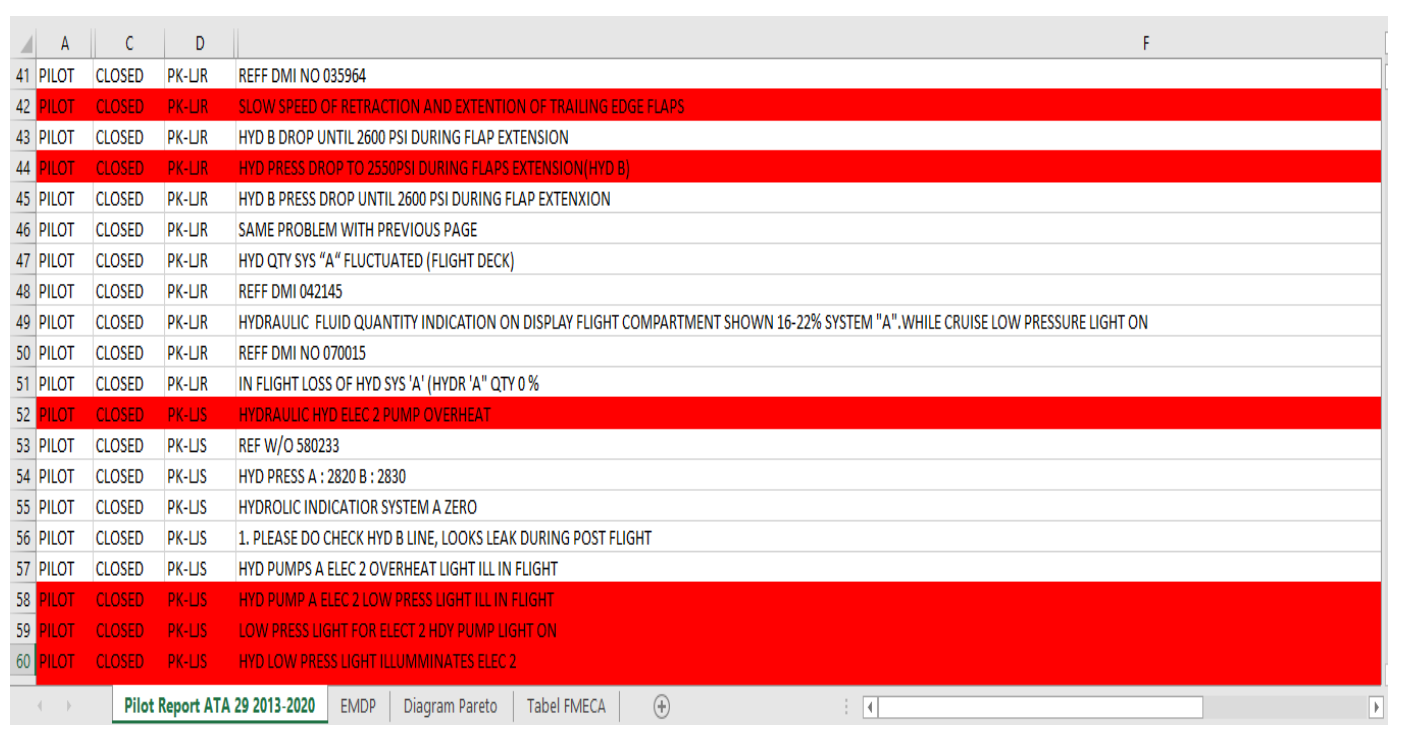

Gambar 1 Sampel Data Berdasarkan Pilot Report ATA 29 Hydraulic

Urutan Pengerjaan alur pengerjaan

a. Pencarian Data

Langkah awal ialah mencari data yang akan dibutuhkan untuk proses analisis. Pencarian data dilakukan dengan mengidentifikasi data, apakah data tersebut sesuai dengan masalah yang akan diteliti. Data yang diambil berasal dari daftar laporan kerusakan sistem Electric Motor-Driven Pump pesawat Boeing 737-800, di Batik Air.

b. Studi Literatur

Dilakukan dengan cara membaca referensi atau buku yang berkaitan guna memahami permasalahan yang akan diteliti.

c. Pengumpulan Data

Setelah data yang dibutuhkan untuk proses analisis ditemukan, maka data tersebut akan dikumpulkan dan dipilah sesuai dengan kebutuhan sebagai langkah awal proses analisis. Dalam hal ini kerusakan pada komponen komponen maupun dari kegagalan sistem Electric Motor-Driven Pump pada pesawat Boeing 737-800.

d. Pengelohan Data

Setelah data dikumpulkan dan dipilih menurut kebutuhan penelitian, di dapat jumlah dari masing-masing kegagalan. Jumlah kegagalan yang didapat kemudian disusun menjadi grafik dimana proses selanjutnya menjadi acuan dalam penentuan jumlah kerusakan/occurrence dalam FMEA.

e. Analisis Data

Dalam penelitian ini menggunakan analisis secara kualitatif dengan menganalisis kinerja dari sistem Electric Motor-Driven Pump dengan menggunakan prinsip dasar dari predictive maintenance. Pelaksanaannya harus didasari dengan pemetaan faktor penyebab kerusakan dari sebuah sistem dengan menggunakan metode Failure Mode and Effect Analysis (FMEA).

f. Kesimpulan dan Saran

Setelah melakukan analisis maka dapat disimpulkan dari penguraian analisis yang dilakukan, sesuai dengan tujuan penelitian. Disamping itu saran dari peneliti untuk berbagai kalangan dapat diutarakan berkaitan dengan penelitian yang dilakukan. 


\section{Hasil dan Pembahasan}

Data yang diperoleh dalam menganalisa pada sistem Electric Motor-Driven Pump adalah Pilot Report (Pirep). Data Pilot Report merupakan data terbaru kondisi suatu pesawat yang sedang beroperasi. Hal ini dikarenakan pilot secara langsung menuliskan kondisi pesawat yang sedang diterbangkan di Aircraft Maintenance Log (AML) jika terjadi suatu keanehan (anomaly) pada pesawat. Setelah pilot menuliskan Pirep maka dokumen tersebut akan dilengkapi oleh maintenance crew sebagai deteksi awal dari kerusakan yang ditulis dalam Pirep yang bernama Maintenance Report (Marep). Data Pilot Report mencakup seluruh tipe pesawat dalam suatu ATA Chapter dimana penelitian ini dilakukan dengan langkah awal mempelajari Pirep dari seluruh tipe pesawat, kemudian mengklasifikasikan laporan-laporan tersebut sesuai dengan tipe pesawat yang bersangkutan. Dari data yang diperoleh, terdapat 546 kasus pada B737-800 ATA Chapter 29 tentang Hydraulic System pada periode 2013 sampai dengan 2020 yang selanjutnya diseleksi untuk didapatkan jenis kasus yang termasuk dalam sistem Electric Motor-Driven Pump saja. Berdasarkan data Pirep yang telah diklasifikasikan terdapat 213 kasus yang termasuk dalam sistem Electric Motor-Driven Pump. Dari data kasus tersebut masih harus diseleksi kembali dikarenakan laporan dari Pirep harus diklasfikasikan kembali berdasarkan kasus yang perlu dianalisa ulang dan kasus yang telah di evaluasi. Data yang telah diklasifikasikan tersebut memberikan hasil berupa 120 kasus yang harus dianalisa ulang. Data pada sistem Electric Motor-Driven Pump tersebut dapat dilihat pada tabel 1 Data Perolehan Pilot Report 2013 s.d 2020.

Tabel 1 Data Perolehan Pilot Report 2013 s.d 2020

\begin{tabular}{|c|l|c|c|c|}
\hline No & \multicolumn{1}{|c|}{ Problem } & Frekuensi & Persen (\%) & Akumulasi (\%) \\
\hline 1 & Hyd Low Press Light Illumminates & 76 & 35,6808 & 35,6808 \\
\hline 2 & Hydraulic Hyd Elec Overheat & 31 & 14,5540 & 50,2347 \\
\hline 3 & Found Small Hyd Leak From Emdp & 13 & 6,1033 & 56,3380 \\
\hline \multirow{2}{*}{$\begin{array}{l}\text { W/O: 640262 " Replace Emdp Case Drain Filter } \\
\text { \#2"; }\end{array}$} & 93 & - & - \\
\hline & & 213 & & 142,2535 \\
\hline
\end{tabular}

Dari Tabel 1 mengenai kasus pada sistem Electric Motor-Driven Pump berdasarkan Pilot Report, didapatkan diagram pareto. Untuk data Pilot Report yang lengkap dapat dilihat pada lampiran 2. Dapat dilihat pada tabel diatas, warna biru menunjukkan kasus low pressure, warna hijau menunjukkan kasus overheat, warna merah menunjukkan kasus leak dan warna kuning menunjukkan kegiatan maintenance. Untuk kegiatan maintenance tidak akan dianalisis karena maintenance tidak termasuk kedalam kasus penyebab terjadinya kegagalan sistem EMDP. Dengan menggunakan analisis Pareto, akan menghasilkan grafik kasus penyebab kegagalan sistem EMDP, grafik tersebut dapat dilihat pada Gambar 2 dibawah ini. 




Gambar 2 Diagram Pareto Berdasarkan Perolehan Pilot Report 2013-2020

Berdasarkan gambar 2 prinsip pareto 80/20 yang menyatakan banyak kejadian atau akibat sebesar $80 \%$ dari total efeknya hanya disebabkan $20 \%$ dari sebabnya. Pareto Analysis bertujuan untuk melihat seberapa besar pengaruh dan seberapa banyak frekuensi dalam kasus tersebut. Diagram pareto adalah grafik batang yang menunjukkan masalah berdasarkan urutan banyaknya jumlah kejadian. Urutannya mulai dari jumlah permasalahan yang paling banyak terjadi sampai yang paling sedikit terjadi. Dalam grafik, ditunjukkan dengan batang grafik tertinggi (paling kiri) hingga grafik terendah (paling kanan). Dari 20\% total jenis kasus yang berjumlah 3 kasus yaitu $20 \%$ x 3 kasus, diperoleh 1 kasus yang merupakan $80 \%$ kejadian atau akibat dari seluruh kasus. Kasus tersebut adalah low pressure. Dari urutan ranking tersebut dapat mendominasi persentase sebesar 35,6808\% dan jumlah frekuensi sebesar 76 kasus selama peride 2013 sampai dengan 2020. Dari satu jenis penyebab yang didapatkan, memberi gambaran bahwa kemungkinan terjadi karena pack illuminated/lampu indikasi pada panel P5 dalam cockpit menyala.Berdasarkan Aircraft Maintenance Manual (AMM) Boeing 737-800 ATA 29 Electric Motor-Driven Pump, lampu indikasi pack illuminated/menyala menunjukkan bahwa adanya penyebab yang mengakibatkan sistem tidak dapat menyuplai tekanan hidrolik untuk itu diperlukan analisis lanjut berupa Failure Mode and Effect Analysis (FMEA) dari Electric Motor-Driven Pump tersebut.

Dari analisis FMEA didapatkan hasil berupa nilai Risk Priority Number (RPN) yang merupakan penilaian risiko setelah dilakukan identifikasi kasus pada Electric Motor-Driven Pump dengan menggunakan metode FMEA. Nilai RPN yang diperoleh menunjukkan tingkat kepentingan terhadap perhatian atau prioritas risiko yang diberikan untuk penyebab yang ada di dalam sistem Electric MotorDriven Pump berdasarkan standar yang telah ditentukan. Pada tabel FMEA Electric Motor-Driven Pump di dapat hasil berupa nilai RPN tertinggi dari Electric Motor-Driven Pump ialah adanya temuan leak pada komponen EMDP, dengan nilai RPN sebesar 80. Hasil dari analisis FMEA menjadi kunci dasar pola pikir dalam penentukan langkah-langkah yang akan dilakakukan untuk mencegah terjadinya indikasi berulang. Adanya leak pada komponen dapat mengakibatkan komponen tidak dapat menyuplai tekanan hidrolik ke sistem sehingga akan mengakibatkan flight control tidak dapat berkerja secara maksimal, sehingga pesawat harus terbang manual atau flight by cable, namun EMDP bersifat stand by pada sistem hydraulic. Apabila EMDP tidak dapat bekerja maka akan di back-up oleh EDP, begitu juga sebaliknya, saat kedua sistem tersebut gagal maka pesawat harus terbang manual (flight by cable) atau selama terbang Auto Pilot tidak dapat diaktifkan. Untuk penjelasan nilai severity, occurrence dan detection yaitu sebagai berikut:

a. Severity (level efek)

Severity adalah sebuah penilaian terhadap tingkat keseriusan suatu efek atau akibat dari potensi kegagalan pada suatu sistem yang berpengaruh pada suatu hasil kerja sistem. Niai severity untuk ketiga kasus yaitu dengan nilai sebesar 4, rank severity menunjukan "sangat rendah - mesin dapat beroperasi dengan baik, namun masih ada tanda-tanda kerusakan minor dari mesin. Adanya kesalahan dalam penyetelan-penyetelan kecil" 
b. Occurrence (level kejadian)

Occurrence adalah sebuah penilaian terhadap tingkatan keseringan dari suatu potensi kegagalan. Dari angka atau tingkatan occurrence ini dapat diketahui kemungkinan terdapatnya kerusakan dan tingkat keseringan terjadinya kerusakan pada sistem. Setiap kasus memiliki nilai occurrence yang berbeda-beda dikarekan tiap kasus memiliki tingkatan keseringan kejadian yang beda, dan untuk tnilai-nilai occurrence, rank of occurrence. Pada kasus pertama memiliki nilai occurrence 8 dikarenakan kasus overheat memiliki jumlah 8 kejadian pada tahun 2018, untuk kasus kedua memiliki nilai sebesar 10 dikarekan kasus leak memiliki jumlah 2 kejadian pada tahun 2018 dan untuk kasus yang terakhir memiliki nilai occurrence sebesar 7 karena kasus low pressure memiliki jumlah 20 kejadian pada tahun 2018.

c. Detection (level deteksi)

Detection adalah sebuah penilaian terhadap tingkat kemudahan mendeteksi suatu potensial kegagalan. Penilaian tingkat detection sangat penting dalam menemukan potensi penyebab kegagalan yang menimbulkan kerusakan. Bedasarkan tabel 4.2 untuk tiap kasus memiliki nilai deteksi yang sama yaitu 2 dikarenakan tiap kasus terjadi lampu indikasi pada panel hidrolik menyala. Nilai 2 tersebut didapatkan dengan mengacu pada tabel di bab 2, tabel 2.3 rank of detection yaitu "peluang sangat tinggi mekanisme yang tersedia untuk mendeteksi penyebab kegagalan pontesial atau modus kegagalan.

Jadi, menimbang hasil dari analisa, merekomendasikan untuk memperketat kembali tindakan Preventive Maintenance terhadap EMDP secara berkala dalam waktu yang singkat, yaitu dengan mempertingkatkan monitoring guna untuk mendeteksi penyebab kegagalan lebih awal. Dengan memperketat Preventive Maintenance tersebut diharapkan kegagalan dari sistem EMDP dapat dihindari sejak dini sehingga EMDP selalu terjaga keandalannya dan meminimalisir resiko yang dapat terjadi, dan juga dapat mengurangi beban cost pergantian komponen yang dikeluarkan. Seperti untuk mengatasi terjadinya leak dapat dilakukan monitoring untuk selalu memastikan kondisi komponen dalam keadaan baik. Serta melakukan monitoring pada sistem pressure pesawat sebelum dilakukan flight oleh engineer agar sistem tersebut dapat dipastikan aman untuk beroperasi dengan baik dalam penerbangan selanjutnya karna bisa dilihat dari hasil analisa nilai RPN pada kasus temuan leak pada komponen memperoleh nilai 80 yang memiliki tingkat kegagalan sedang. Penulis sangat mengerti betapa pentingnya setiap komponen apapun didalam pesawat untuk terus dijaga keandalannya demi menjaga kualitas pesawat tersebut. Oleh karena itu, melakukan tindakan Preventive Maintenance yang tepat dan secara berkala adalah hal yang sangat penting dalam setiap perawatan komponen pesawat terbang.

\section{Kesimpulan}

Dari hasil perhitungan nilai RPN (Risk Priority Number) didapatkan nilai untuk kasus overheat yaitu 64 yang memiliki tingkat kegagalan sedang, untuk kasus temuan leak pada komponen yaitu 80 yang memiliki tingkat kegagalan sedang dan untuk kasus yang terakhir yaitu low pressure memiliki nilai sebesar 56 yang memiliki tingkat kegagalan rendah. Dari hasil analisa dengan metode FMEA didapatkan hasil berupa nilai RPN tertinggi dari Electric Motor-Driven Pump ialah adanya temuan leak pada komponen EMDP, dengan nilai RPN sebesar 80 yang memiliki tingkat kegagalan sedang. Nilai tersebut hasil dari perkalian nilai severity, occurrence dan detection. Peyebab potensial (penyebab dominan) dari kasus kegagalan ini merupakan low pressure pada komponen EMDP dengan nilai RPN 56. 


\section{Daftar Pustaka}

[1] Suwondo, Edy. 2001. Diklat Kuliah Manajemen Perawatan Pesawat. Bandung: Institut Teknologi Bandung.

[2] Suwondo, Edy. 2009. Diklat Kuliah Maintenance Conrolled by Reliability Methods. Bandung: Institut Teknologi Bandung.

[3] Nugraha, Palagani Dian. 2016. Preventive Maintenance Pada Air Conditioning Pack Cooling System Pesawat Boeing 737-800. Skripsi. Teknik Penerbangan, Sekolah Tinggi Teknologi Adisutjipto, Yogyakarta.

[4] Saffanah, Hasna. 2018. Analisis Kerusakan Komponen Kritis Mesin Di Bagian Persiapan Devivi Processing PT Gistex Textile- Division Menggunakan

[5] Metode FMECA. Tugas Akhir. Teknik Industri, Universitas Komputer Indonesia, Bandung.

[6] Istiqomah, Anindia. 2020. Analisis Kegagalan Air Conditioning System Boeing 737 NG Dengan Metode Failure Mode and Effect Analysis (FMEA).

[7] Harry A. Kinnison, dan Tariq Siddiqui. Aviation Maintenance Management. MC Graw Hill.

[8] Training Manual, ATA Chapter 29 Hydraulic System

[9] Component Maintenance Manual 29-20-15 